\title{
The Effect of Low Temperature Air Plasma Treatment on Physico-chemical Properties of Kaolinite/Polyethylene Composites
}

\author{
Ivo Krásný ${ }^{1,2}$, Lubomir Lap ${ }^{\gtrless}{ }^{* 1,2,3}$, Barbora Lap ${ }^{*} \operatorname{ková}^{1,2,3}$, Richard W. Greenwood ${ }^{4}$, \\ K] tha Salthor ${ }^{3}$, Neil A. Rowson ${ }^{4}$ \\ ${ }^{1}$ Center of Polymer Systems, Tomas Bata University in Zlin, Faculty of Technology, \\ Nam. T.G. Masaryka 5555, Zlin, Czech Republic \\ ${ }^{2}$ Tomas Bata University in Zlin, Faculty of Technology, Inst. Foodstuff Technology, Nam. T.G. \\ Masaryka 275, Zlin, Czech Republic \\ ${ }^{3}$ Regional Centre of Advanced Technologies and Materials, Department of Physical Chemistry, \\ Faculty of Science, Palacky University, 17. listopadu 12, 77146 Olomouc, \\ Czech Republic \\ ${ }^{4}$ Department of Chemical Engineering, University of Birmingham, Edgbaston, \\ Birmingham B15 2TT, UK
}

*Corresponding author. E-mail: $\underline{\text { lapcik1@ seznam.cz }}$

\begin{abstract}
The effect of low temperature air plasma treatment on the physico-chemical properties of kaolinite/polyethylene composites was studied. Moreover, the kaolin powder was treated with (3aminopropyl)triethoxysilane as a coupling agent to improve the interfacial adhesion between powder filler and polymer matrix. The modification of the kaolin resulted in a notable improvement in the mechanical strength and elastic modulus of filled polyethylene composites, compared to the virgin polymers. Observed improvement of the tensile strength became more marked as the filler loading increased, indicating an improved degree of filler/matrix interaction. Simultaneously the improvement of the fracture toughness of prepared HDPE and LLDPE kaolinite composites was confirmed. Moreover, the morphology of the grains distribution and tensile fracture surface was examined by electron microscopy confirming excellent distribution of the filler in the polymer matrix.
\end{abstract}

Keywords: A. Polymer-matrix composites (PMCs); A. Particle-reinforcement; A. Thermoplastic resin; B. Fracture toughness; B. Plastic deformation; D. Mechanical testing; D. Thermal analysis 


\section{Introduction}

Characterization and modification of polymers are perhaps the most important aspects of polymer research, production and applications. Polyolefin polymers, especially thermoplastics have become an essential part of our everyday lives in the last few decades [1,2]. Thermoplastics, such as polyethylene (PE) can offer useful mechanical, chemical, electrical properties, with low density, high formability and the ability to be recycled. Due to its low price per unit volume and its unique physico-chemical properties it is therefore, the world's number one per volume most used thermoplastic [3,4]. This semi-crystalline polymer can be classified according its density and divided into four groups: high density polyethylene (HDPE), low density polyethylene (LDPE), linear low density polyethylene (LLDPE), and very low density polyethylene (VLDPE) [5].

In the last few years, clay minerals were used as a cost reducer and as an additive triggering an improvement of the mechanical properties of polymer composites. Their surface modifications were used in catalysis, as an adsorbent, in sensors and as filler in polymer-clay composite systems [6]. The effect of incorporating inorganic fillers into the thermoplastic polymer network, results in the improvement of the physico-chemical and mechanical characteristics such as low air permeability, improved mechanical strength, modulus of elasticity and stiffness [7-11]. For this reason the research and development activities focused on composites containing inorganic filler is of expanding importance. Matrix modification, degree of crystallinity, type of reinforcement, quality of adhesion between filler and matrix, size, shape, size distribution of filler particles, addition of coupling agents affects the physico-chemical and thermo-mechanical properties, as well as internal structure and strength of aggregates [12-15]. In most cases, silane coupling agents are added to react with inorganic substrates in order to form stable covalent bonds, thus altering the physical interactions of treated polymer/filler substrates. As is very well known, polymer/kaolin interface quality performance is essential for excellent overall composite system material/mechanical properties, where exact adjustment of the polymer matrix modulus and adhesive bond strength is vital for final synergistic increase of mechanical strength of the composite system [16]. An effect of coupling agents on mechanical properties improvement of polymer/inorganic filler composites was studied and referenced in early works of Arkles et al. [17], Edwin. et al. [18] and Leyden. [19].

Kaolin is a clay mineral also known as China Clay or Paper Clay. The chief constituent of Kaolin $\left(\mathrm{Al}_{2} \mathrm{O}_{3} 2 \mathrm{SiO}_{2} \mathrm{H}_{2} \mathrm{O}\right)$, is kaolinite, which consists of successive layers of octahedral alumina and tetrahedral silica, which alternate to form plate like hexagonal particles. The particles are flat disks or plate like in shape, with the disk radius of the order 5-10 times larger than the thickness. Thus a typical crystal is a platelet of 0.51 microns in diameter and 0.1 microns thick. The flat surface is 
negatively charged over the entire $\mathrm{pH}$ range, whilst the edges are positive at low $\mathrm{pH}$, but negative at high $\mathrm{pH}$, with an iso electric point at about $\mathrm{pH}$ 7. These edge effects arise due to the fracture of the lattice network and contain silica and alumina like sites $[20,21]$. The electrokinetic behaviour of kaolinite should show an average of the surface and edge properties, but initial experiments revealed that the zeta potentials were negative over the entire $\mathrm{pH}$ range and were very similar to the silica zeta potential $\mathrm{pH}$ curve. This was explained by the large face to edge surface area ratio [20, 21]. Particle characterization of this clay mineral has previously been studied in our another paper by Lapcik et al. [20] and Greenwood et al., [21].

The mechanical properties of particulate-polymer composites depend strongly on the particle size, particle matrix interface adhesion and particle loading [22, 23]. Polymer composites are noted to show mechanical properties which depend on time, deformation rate and temperature. However, the filler introduces a high amount of interface in the matrix that affects the polymer crystallization process and modifies the structure of the polymer in the neighborhood of the particle surface [22, 24].

The main aim of this paper was focused on studying the effect of low temperature air plasma treatment and silane coupling agent modification of nano/micro kaolinite filler particles on the physico-chemical, mechanical and thermal properties of polyethylene/kaolinite composite system with filler content ranging from 0 to $25 \mathrm{wt} . \%$.

\section{Materials}

Two commercial polyethylenes were used in this study: HDPE TIPELIN 6300B and LLDPE LITEN, Unipetrol PND 33-300 (Czech Republic). As a virgin filler material kaolin (Imerys Minerals Ltd, Cornwall, UK) was used. For chemical modification of kaoline a silane coupling agent (3aminopropyl)triethoxysilane (Sigma Aldrich, USA) was used.

\section{Methods}

\subsection{Sample preparation}

Air plasma treatment of the filler powder was performed in a Diener Femto (Diener Electronic, Germany) plasma reactor operating at $13.56 \mathrm{MHz}$ frequency for $10 \mathrm{~min}$., with generator power 100 $\mathrm{W}$, air flow rate $5 \mathrm{~cm}^{3} / \mathrm{min}$ and processing pressure $35 \mathrm{~Pa}$. The polymers were filled with virgin and plasma treated kaolinite powder with the following content: $0,2.5,5,7.5,10,15$ and 25 wt $\%$.

From a processing point of view, the important attitude was favourable dispersion of filler particles and minimizing their agglomeration. The latter agglomeration is probably due to the high surface energy of kaolin fillers [25]. Filled, homogenized polyethylenes were then injection-moulded in an 
Arburg Allrounder $170 \mathrm{U}$ 150-30 (Germany) machine in a form of a dogbone testing articles according to the CSN EN ISO294-1 and CSN ISO 293 standards. The processing parameters of the injection-moulding process used are shown in Table1.

Chemical modification of kaolin was realized using silane coupling agent (3-aminopropyl) triethoxysilane (Sigma Aldrich, USA) as a intercalation process supporter. The modification was performed with $3 \%$ vol. addition in 1:1 water-ethanol solution. Afterwards the substrate was stirred for 180 minutes by homogenizer at room temperature $24^{\circ} \mathrm{C}$ and then dried.

\subsection{Tensile strength testing}

Tensile strength measurements were performed with moulded dogbone testing articles (length of $75 \mathrm{~mm}$ ) using universal testing machine ZWICK 1456 (Germany). Measurements were performed at 50 and $200 \mathrm{~mm} / \mathrm{min}$ deformation rates. Each measurement was repeated five times and mean average values were calculated. There were determined an ultimate tensile strength $\left(\mathrm{F}_{\max }\right)$, elongation at break ( $\mathrm{B}$ ) and elastic modulus (E) of a series of composites with varying filler content. Observed results are summarized in Tables 2-5.

\subsection{Charpy V-notch impact test}

The notched impact toughness was determined according to the TL 52631 standard on Charpy's hammer (0.4 kPm hammer) (CEAST Resil Impactor Junior, (Germany)) at $25{ }^{\circ} \mathrm{C}$ for each material under study. Each measurement was repeated five times. V-notched specimens were of the $5 \times 3 \times 58 \mathrm{~mm}$ dimensions with notch depth of $2 \mathrm{~mm}$.

\subsection{Scanning Electron Microscopy}

Scanning electron microscopy was used to follow fracture surface and filler particles morphology characteristics of the virgin and modified samples. Scanning electron microscopy (SEM) images were captured on a Hitachi 6600 FEG microscope (Japan) operating in the secondary electron mode and using an accelerating voltage of $1 \mathrm{kV}$.

\subsection{Thermal Analysis}

Thermo-gravimetry (TG) and differential thermal analysis (DTA) experiments were performed on simultaneous DTA-TG apparatus (Shimadzu DTG 60, Japan). Throughout the experiment, the sample temperature and weight-heat flow changes were continuously monitored. 
Conditions of measurement: Heat flow $10^{\circ} \mathrm{C} / \mathrm{min}$ and dynamic atmosphere of nitrogen $\left(\mathrm{N}_{2}-50\right.$ $\mathrm{ml} / \mathrm{min}$ ), range of temperature measurement was from $40{ }^{\circ} \mathrm{C}$ to $500{ }^{\circ} \mathrm{C}$.

\section{Results and Discussion}

Figure 1 shows results of the tensile strength measurements for virgin and chemically modified plasma treated filler particles composites with HDPE. It is evident, that the highest increase in ultimate tensile strength was found for the chemically modified filler at $7.5 \mathrm{w} . \%$ concentration. Here the absolute increase of $\mathrm{F}_{\max }$ was found to be from $30.50 \mathrm{MPa}$ to $32 \mathrm{MPa}$ for deformation rate of $50 \mathrm{~mm} / \mathrm{s}$. In the filler concentration range of 2.5 to $7.5 \mathrm{w} . \%$ a plateau region of $F_{\max }$ was found, indicating highest mechanical strength of the studied material for both deformation rates. A minor effect was found for chemically + plasma treated filler. However, by plasma treatment the mechanical strength as indicated by $F_{\max }$ parameter was continuously decreasing from $31 \mathrm{MPa}$ at 2.5 w.\% filler content to $30.18 \mathrm{MPa}$ at $15 \mathrm{w} . \%$ filler content. A similar pattern was found for LLDPE polymer composite as shown in Figure 2. Results of the latter experiments are summarized in Tables $2-4$.

However, for higher deformation rates the tensile strength was increased, suggesting lowered mobility of the macromolecular chains. This triggers their higher stiffness as reflected by a three fold decrease of elongation at break with increasing degree of filling from the initial value of $24 \%$ to 7,8 $\%$ as obtained for $50 \mathrm{~mm} / \mathrm{min}$ deformation rate (see Fig.3). A similar decreasing trend of elongation at break was found also for deformation rate of $200 \mathrm{~mm} / \mathrm{min}$ by factor of 3 for both composites under study.

The Elastic modulus (Fig.5 and Fig.6) increased with the increasing filler content, which can be attributed to improvement in stiffness of kaolin/polymer composites, as reported earlier by Das et al. [26]. This was observed for both studied composites in a similar fashion. This observed increase of the modulus is a result of the increased brittleness of the samples as reflected in decreasing elongation at break for both studied polymer matrices and in the whole filler concentration range.

Fracture toughness measurements were performed at room temperature of $24^{\circ} \mathrm{C}$. It was found that the fracture toughness of both the studied composite systems (virgin kaolinite, plasma treated kaolinite and their silane modifications as fillers) steadily increased with increasing filler content. We must consider a complex nature of the observed behaviour, where for concentrations $10 \mathrm{w} . \% \mathrm{a}$ maximum value was found to be $22 \mathrm{~kJ} / \mathrm{m}^{2}$ and $18 \mathrm{~kJ} / \mathrm{m}^{2}$ respectively. A graphical representation of the latter dependencies is shown in Figures 7 and 8.

To follow the macroscopic changes of the polymer matrix the SEM measurements were performed. These are shown in Figures 9 to 12. As is very well known, for mechanical behaviour of 
polymers, it is typical its time dependency, already from small deformations. What are important here are irreversible deformations, which are generated after exceeding the limiting value, in the case of solid polymers known as upper yield stress. However, we are not able to describe the polymer plasticity only by mechanical friction of structural elements, due to the fact that in comparison to the real mechanical friction it is time and temperature dependent. External stresses create permanent changes in the structure of polymer materials. The latter structural changes are either localized or they target wider volume of the body. Local damage leads to the fracture, while permanent changes act at the wider volume and mostly have the character of the plastic deformation. A typical pattern observed for HDPE is shown in Figure 9, where individually localized shearing bands were found. If the material consistency is accompanied by wider plastic deformation, then ductile fracture is observed. In contrast to the latter ductile fracture, the fracture proceeding in the elastic deformation area is the brittle fracture. In all experiments performed in this study, no observations of purely brittle fracture were found. Ability to undergo plastic deformation is very important for practical applications of polymer materials, because it allows absorption and scattering of the mechanical energy into the large polymer volume thus protecting its concentration into the area of hazardous craze. It is responsible for effective mechanical energy dissipation in the material body. As can be seen in Fig 10 and 12, HDPE and LLDPE/kaolin composite modified of (3-aminopropyl) triethoxysilane with 7.5 w.\% degree of filling revealed a homogenous distribution of kaolin when incorporated in the synthetic polymer matrix. Stress concentration develops around the particles under the effect of external load and actual stress distribution explores the local micro-mechanical deformation processes in heterogeneous polymer systems similarly as in the previous paper [27]. According to the literature, in particulate filled polymers the dominating deformation mechanism is the separation of the matrix/filler interface, i.e. debonding, which leads to a volume increase during deformation [28]. However, in this study, we have found for all samples an excellent polymer/filler adhesion, resulting in creation of small crazes at the end part of the filler particles immersed in the matrix, oriented perpendicularly to the applied mechanical deformation. This behaviour is typical for ductile fracture mechanism. As visible from Figures 10 and 12 typical crazes were localized at the edges of the mineral filler particles (kaolinite) which were acting as the points of the stress localization during mechanical tensile testing. At the beginning of the deformation process distortion plasticity yield belts oriented in the direction of the maximum shear stress (obliquely to the tensile direction) were observed (see Figures 9 and 11) for both HDPE and LLDPE polymer samples. These then may continue their development by means of the neck propagation. However, at the higher deformations in the case of the filled polymer matrices similarly as in the case of virgin HDPE and LLDPE typical crazes were found (see Figures 10 and 12). Plastically deformed fortified material 
is a natural barrier against growth of the crack. The magnitude of such a barrier also depends on testing body geometry. In the case of the planar tightness plastic zones can be most fully developed. In contrary at the conditions of the planar deformation, which are prevailing in the central layer of the thick board, suppress plasticity and favours initiation of the brittle fracture. However, there is not a clear sharp boundary between localized (brittle) and volume (ductile) dislocation. Even at the brittle (or quasi-brittle) fracture it is possible to find at the fracture area layers of plastically transformed (oriented) polymer. However a plastic deformation never covers the whole volume of the testing body evenly.

In Table 5 are summarized results of the thermal analysis of the studied PE composite systems. There were determined parameters such as melting point temperature $\left(\mathrm{T}_{\mathrm{m}}\right)$, enthalpy of fusion at the melting point $\left(\mathrm{HH}_{\mathrm{m}}\right)$, degree of crystallinity, position of the first exothermic peak $\mathrm{T}_{\text {exo }}$ and degree of crystallinity (Xc) calculated according to Jung et al. [29-31]. As given in Table 5, with increasing degree of filling of PE polymer macromolecular matrix a decrease of the fusion enthalpy was found to be accompanied with a decrease of the melting point temperature. This fact indicates successful disruption of the PE macromolecular oriented higher degree structure. When crystallized from dilute solution, PE polymers display the characteristic platelet or lamella structure. It has been well established, that the chain axes are preferentially normal to the wide faces of the lamella. Hence, a given polymer molecule must traverse a crystallite many times. Based on earlier electron microscopy observations, it has been presumed that this interface is comprised of regularly folded chains. However approximately $15-20 \%$ of the chain units must be in non-ordered conformations. This triggers the conclusion that the presence of such a large number of non-crystalline chain units leads to the presence of a disordered amorphous overlayer [30]. The above conclusions correspond well to our findings as with an increasing degree of filling the crystallinity decreased as well (see Table 5).

\section{Conclusions}

The effect of low temperature air plasma treatment and silane coupling agent modification of the surface properties of kaolin based nano filler used for preparation of polyethylene composites (both HDPE as well as LLDPE) was studied. The effect on the final composite physico-chemical, mechanical and thermal properties was studied over a wide range of degrees of filling. It was found that the silane coupling agent surface modification had the strongest effect resulting in improved mechanical properties. Mainly the improvement of the fracture toughness of prepared HDPE and LLDPE kaolinite composites was confirmed. Simultaneously there was also found a tensile strength and elastic modulus increase with increasing degree of filling. Dispersion quality and the morphology of the fracture interface were confirmed by SEM experiments. Here, typical shearing bands due to the 
progressing plastic deformation of the PE macromolecules were found which in the case of the presence of the filler kaolin particles generate cracks creation due to the brittle mode of the fracture process.

\section{Aknowledgements}

Financial support from the Operational Program Research and Development for Innovations European Regional Development Fund (grants CZ.1.05/2.1.00/03.0058 and CZ.1.05/2.1.00/03.0111) and of Tomas Bata University in Zlin Internal Grant Agency (project no. IGA/FT/2013/001) are gratefully acknowledged. Authors would like to express their gratitude also to Erasmus EU teaching staff and student exchange program for partial financing of the project. Special thanks also to Assoc

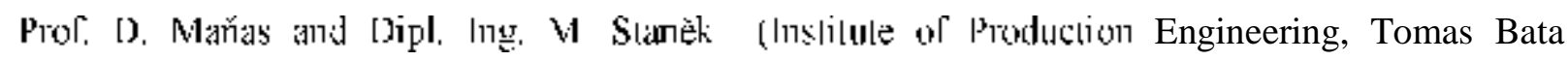
University in Zlin) for their kind assistance during sample preparation.

\section{References}

1. Maiti S. Analysis and Characterization of Polymers. Anusandhan Prakashan-Midnapore 2003.

2. Rothon RN, Hancock M. Particulate-Filled Polymer Composites. Rapra Technology-2nd ed., UK 2003.

3. Malpass BD. Introduction to Industrial Polyethylene. Wiley-Scrivener Publishing, USA 2010.

4. Bing X, Peiping Z, Yinshan J, Mengmeng S, Darui L, Lixin Y. Preparation and characterization of linear low-density polyethylene/dickite nanocomposites prepared by the direct melt blending of linear low-density polyethylene with exfoliated dickite. J Appl Polym Sci 2011; 120(3):1736-43.

5. Wei Y. Understanding precision polyolefins by solid state nuclear magnetic resonance spectroscopy and X-ray scattering. PhD thesis-2010. University of Florida.

6. Peng L. Polymer modified clay minerals: A review. Appl Clay Sci 2007;38:64-76.

7. Privalko VP, Balta Calleja DI, Sukhorukov DI, Privalko EG, Walter R, Friedrich K. Compositiondependent properties of polyethylene/Kaolin composites: Part II Thermoelastic behaviour of blowmoulded samples. J Mater Sci 1999;34(3):497-08.

8. Lapcik L, Jindrova P, Lapcikova B, Tamblyn R, Greenwood R, Rowson N. Effect of the Talc Filler Content on the Mechanical Properties of Polypropylene Composites. J Appl Polym Sci 2008;110(5):2742-47.

9. Domka L, Malicka A, Stachowiak N. The effect of kaolin modification of silane coupling agents on the properties of the polyethylene composites. Pol J Chem Technol 2008;10(2):5-10.

10. Unal H, Findik F, Mimaroglu A. Mechanical Behavior of Nylon Composites Containing 
Talc and Kaolin. J Appl Polym Sci 2003;88(7):1694-97.

11. Ansari DM, Price GJ. Correlation of mechanical properties of clay filled polyamide mouldings with chromatographically measured surface energies. Polymer 2004;45(11):3663-70.

12. Wang M, Deb S, Bonfield W. Chemically coupled hydroxyapatite-polyethylene composites: Processing and characterisation. Mater Lett: Elsevier BV 1999;44(2):119-24.

13. Da Silva ALN, Rocha MCG, Moraes MAR, Valente CAR, Coutinho FMB. Mechanical and rheological properties of composites based on polyolefin and mineral additives. Polym Test 2002;21(1):57 -60.

14. Privalko EG, Pedosenko AV, Privalko VP, Walter R, Friedrich K. Composition-dependent properties of polyethylene/kaolin composites. i. degree of crystallinity and melting behavior of polyethylene. J Appl Polym Sci 1999;73(7):1267-71.

15. Privalko VP, Korskanov VV, Privalko EG, Walter R, Friedrich K. Composition-dependent properties of polyethylene/kaolin composites - VI. Thermoelastic behavior in the melt state. J Therm Anal Calorim 2000;59:509-16.

16. Gelest Ldt.: Hydrophobicity, hydrophilicity and silane surface modification [online]. Gelest, [cit. 1.11.2013]. http://gelest.com/goods/pdf/Hydrophobicity.pdf

17. Arkles B. Tailoring Surfaces with Silanes. Chemtech 1977;7:766-78.

18. Plueddemann EP, Plenum. Silane coupling agents. J Polym Sci: Polym Lett Ed 1983;21(6):503.

19. Leyden D. Silanes, surfaces, and interfaces: proceedings of the Silanes, Surfaces, and Interfaces. Symposium Snowmass, Taylor \& Francis Inc.Colorado 1985. ISBN-13: 9782881240850.

20. Lapcik L, Lapcikova B, Krasny I, Kupska I, Greenwood RW, Waters KE. Effect of Low Temperature Air Plasma Treatment on Wetting and Flow Properties of Kaolinite Powders. Plasma Chem Plasma P 2012;32(4):845-58.

21. Greenwood RW, Lapcikova B, Surynek M, Waters KE, Lapcik L. The zeta potential of kaolin suspensions measured by electrophoresis and electroacoustics. Chem Pap 2007;61:1-10.

22. Fu S-Z-Y, Feng X-Q, Lauke B, Mai Y-W. Effects of particle size, particle/matrix interface adhesion and particle loading on the mechanical properties of particulate-polymer composites. Composites: Part B 2008;39:933-961.

23. Liang J-Z. Reinforcement and quantitative description of inorganic particulate-filled polymer composites. Composites: Part B 2013;51:224-232.

24. Chen J, Yan N. Crystallization behaviour of organo-nanoclay treated and untreated kraft fiberHDPE composites. Composites: Part B 2013;54:180-187. 
25. Bahlouli N, Cavaille JY, Garcia-Ramirez M, Camara A, Imam SH, Greene RV, Zaidi BR. Thermo-Mechanical Behavior of Polyethylene Reinforced by Ligno-Cellulosic Fillers. ACS Symposium series- Biopol Adv Mat 1999;723(6):65-76.

26. Das SN, Khastgir TK, Chakraborty DK. Effect of Filler Blend Composition on the Electrical and Mechanical Properties of Conductive AVE Composite. Project Euclid 2002;8:457-634.

27. Bucknall CB. Toughened Plastics. J Appl Sci 1978;16(7):376.

28. Pukánszky B, van Es M, Maurer FHJ, Vôrôs G. J. Mater Sci 1994;29:2350.

29. Jung J, Kim J, Uhm YR, Jeon JK, Lee S, Lee HM, Rhee CK. Preparations and thermal properties of micro- and nano-BN dispersed HDPE composites. Thermochim Acta 2010;499;8-14.

30. Mandelkern L, Allou AL, Gopalan M. Enthalpy of fusion of linear polyethylene. J Phys Chem 1968;72;309-318.

31. Thermal Analysis Application No. UC 134. Mettler Toledo Thermal Analysis UserCom 13; 2010;134:1-3. 


\section{Figure caption:}

Fig.1: Kaolin filler concentration dependence of the ultimate tensile strength (Fmax) for HDPE at a deformation rate of $50 \mathrm{~mm} / \mathrm{min}$.

Fig.2: Kaolin filler concentration dependence of the ultimate tensile strength $\left(\mathrm{F}_{\max }\right)$ for LLDPE at a deformation rate of $50 \mathrm{~mm} / \mathrm{min}$.

Fig.3: Kaolin filler concentration dependence of the elongation at break for HDPE at a deformation rate of $50 \mathrm{~mm} / \mathrm{min}$.

Fig.4: Kaolin filler concentration dependence of the elongation at break for LLDPE at a deformation rate of $50 \mathrm{~mm} / \mathrm{min}$.

Fig.5: Kaolin filler concentration dependence of the elastic modulus (E) for LLDPE in deformation rate of $50 \mathrm{~mm} / \mathrm{min}$.

Fig.6: Kaolin filler concentration dependence of the elastic modulus (E) for HDDPE in deformation rate of $50 \mathrm{~mm} / \mathrm{min}$.

Fig.7: Fracture toughness of HDPE composite as a function of kaolinite filler concentration dependence.

Fig.8: Fracture toughness of LLDPE composite as a function of kaolinite filler concentration dependence.

Fig.9: SEM images of HDPE fracture surface.

Fig.10: SEM image of HDPE/silane coupling agent modified kaolinite fracture surface.

Fig.11: SEM image of LLDPE fracture surface.

Fig.12: SEM image of LLDPE/silane coupling agent modified kaolinite fracture surface. 


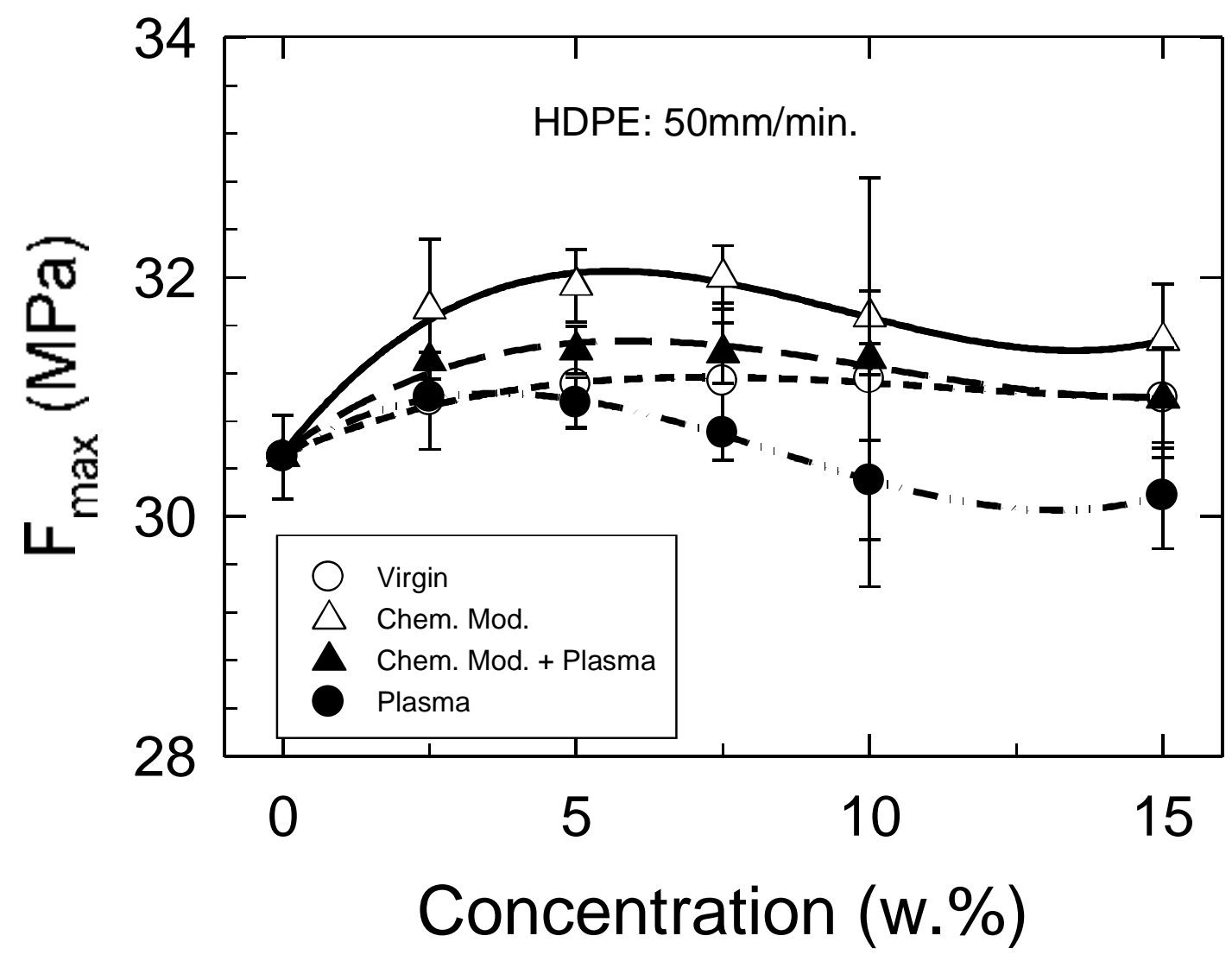

Fig. 1. 


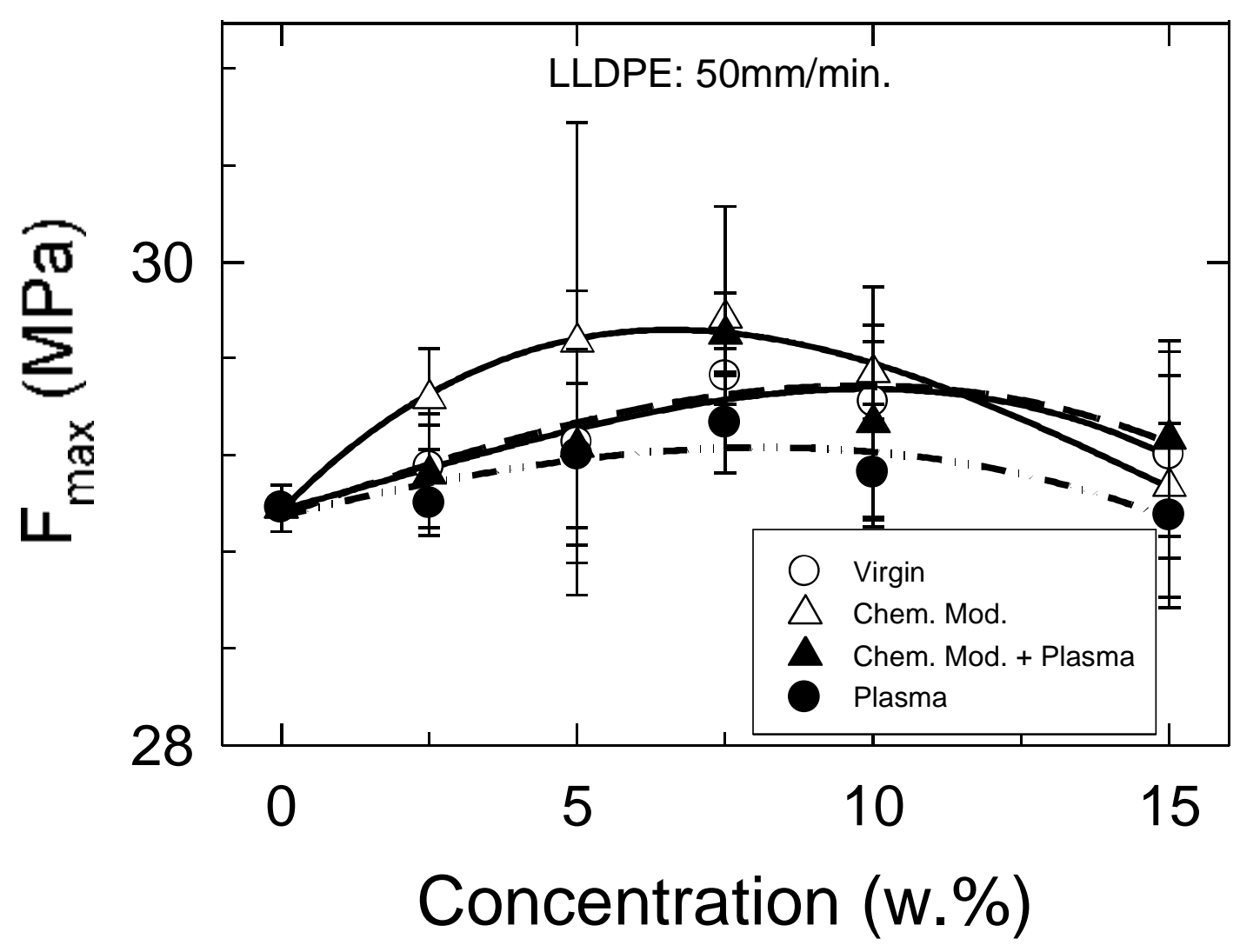

Fig.2. 


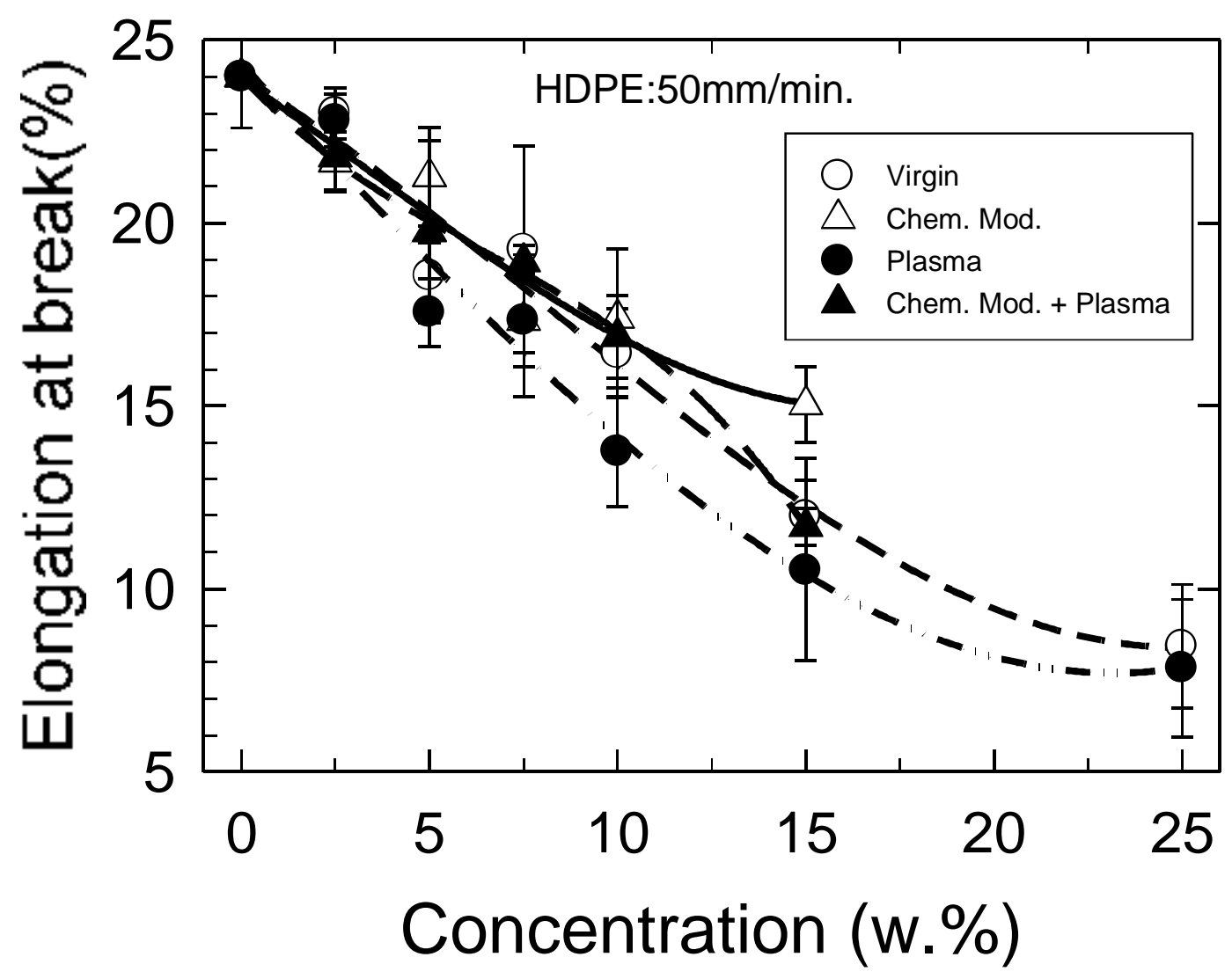

Fig.3. 


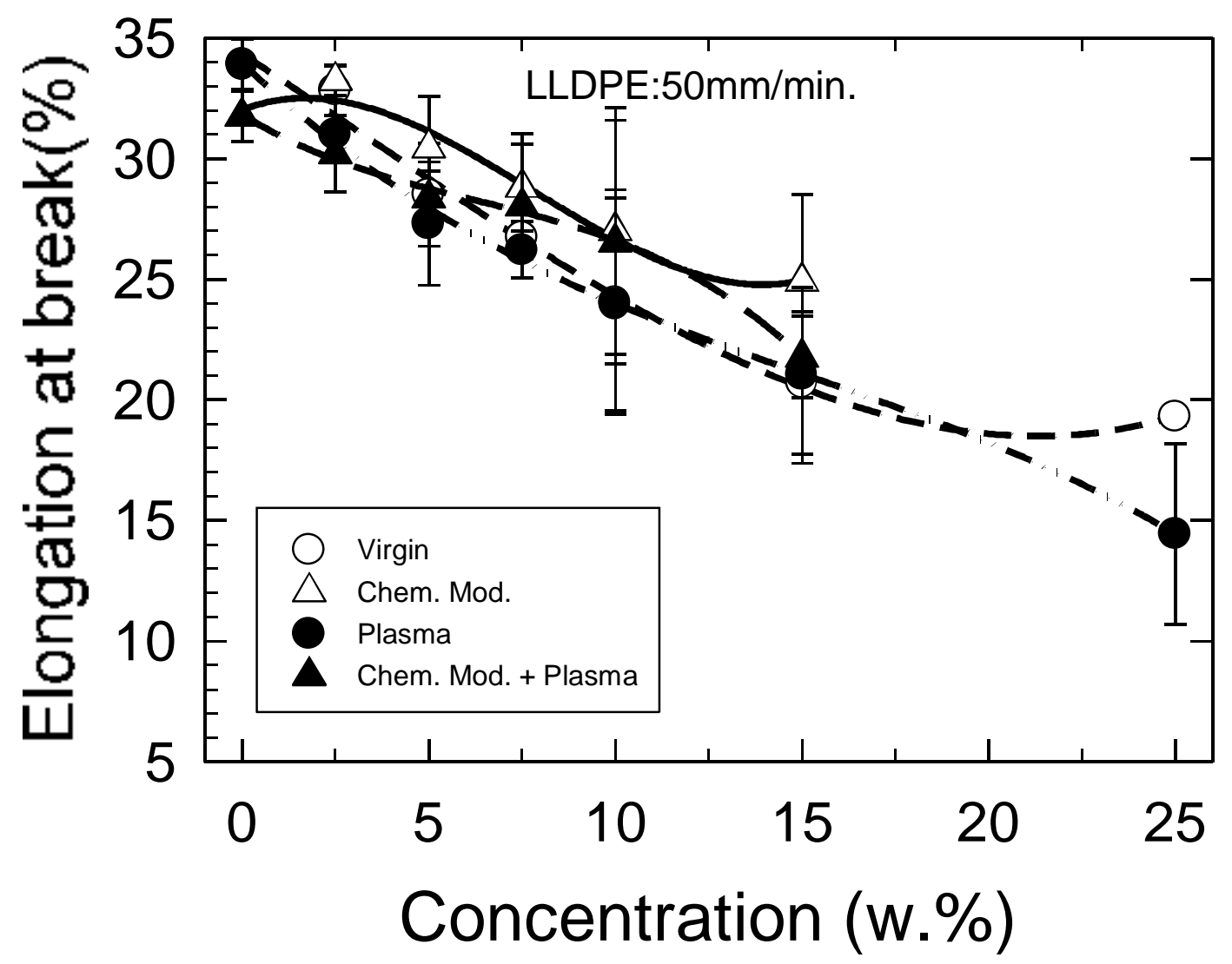

Fig.4. 


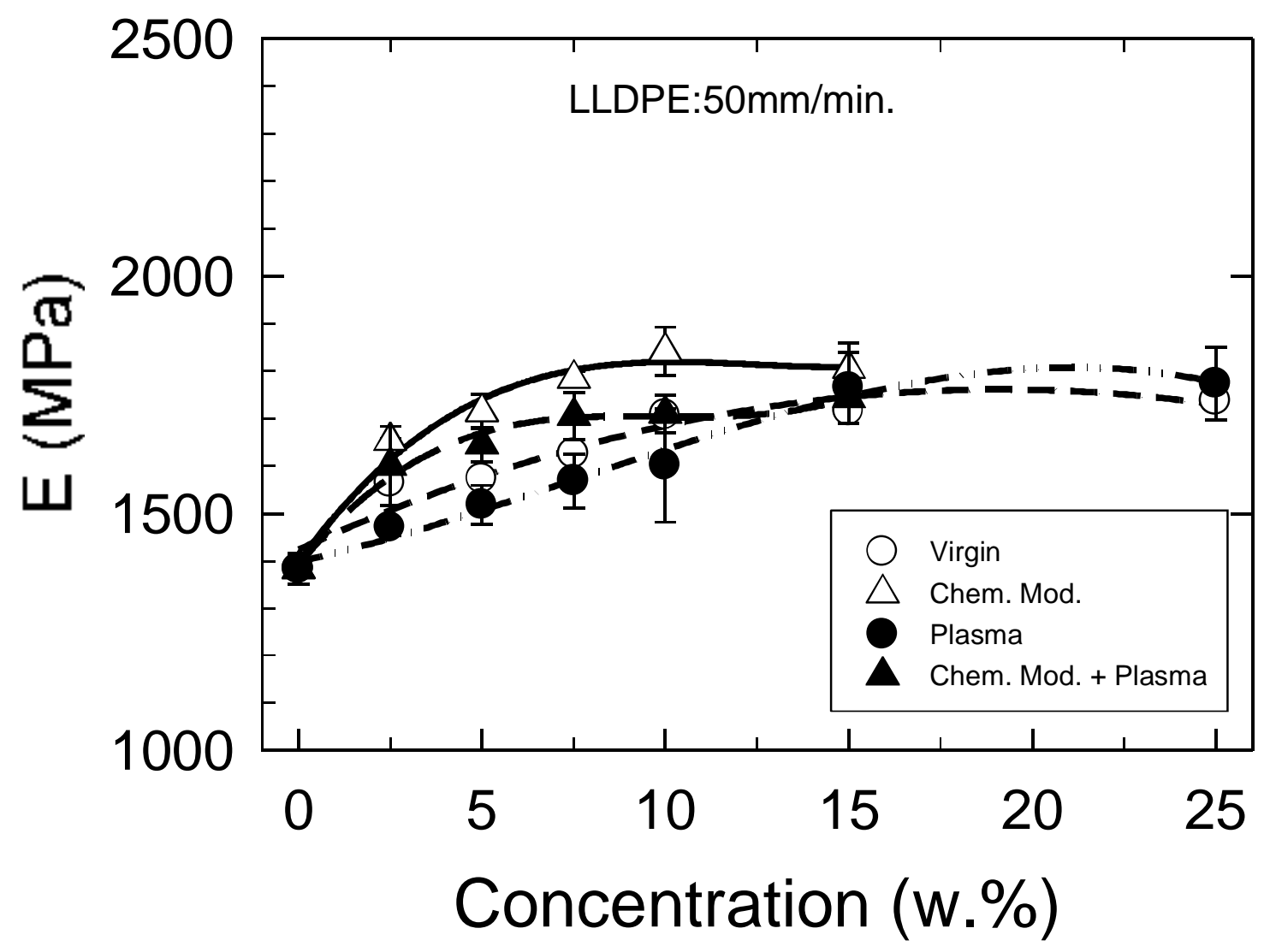

Fig.5. 


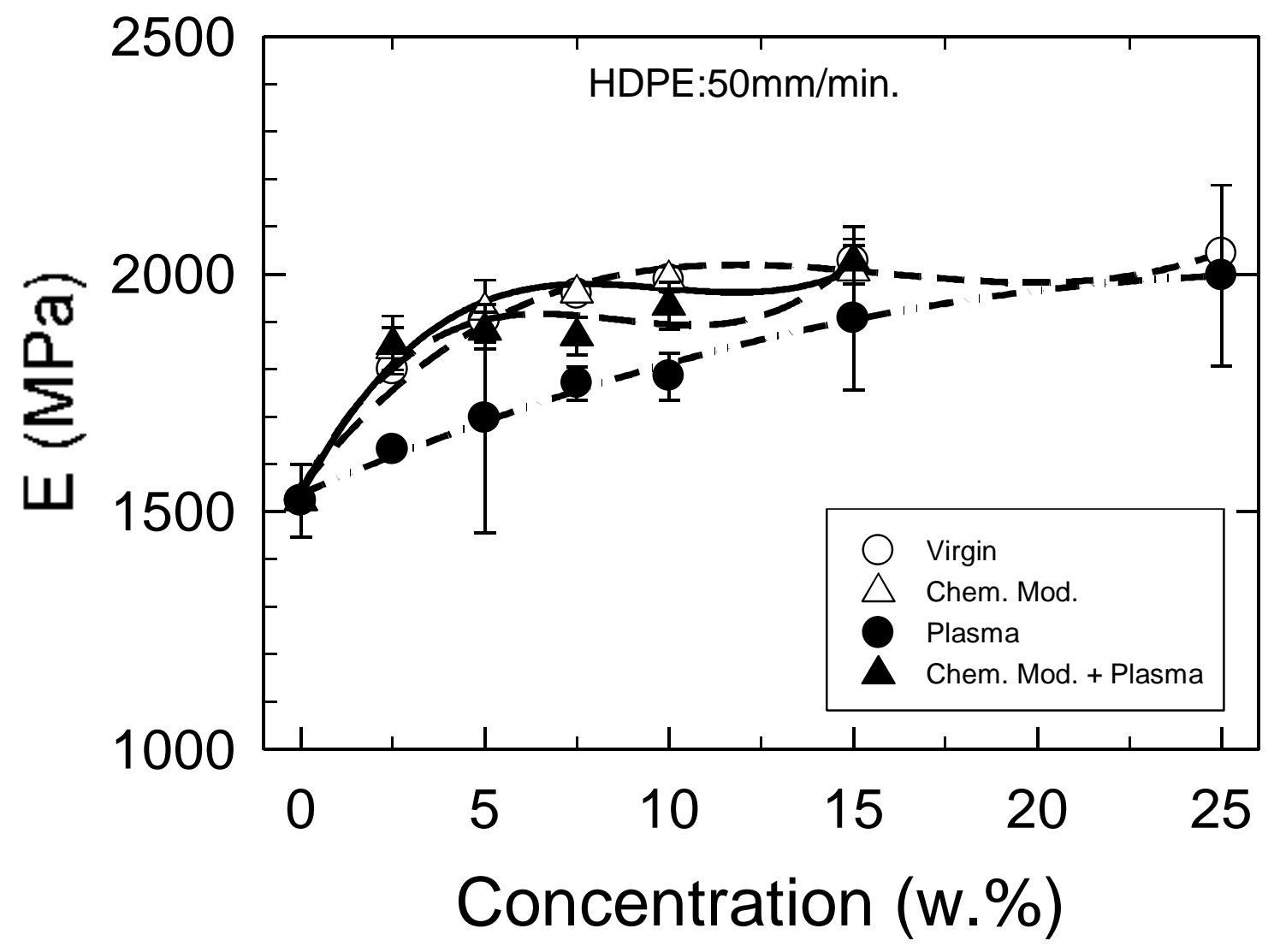

Fig.6. 


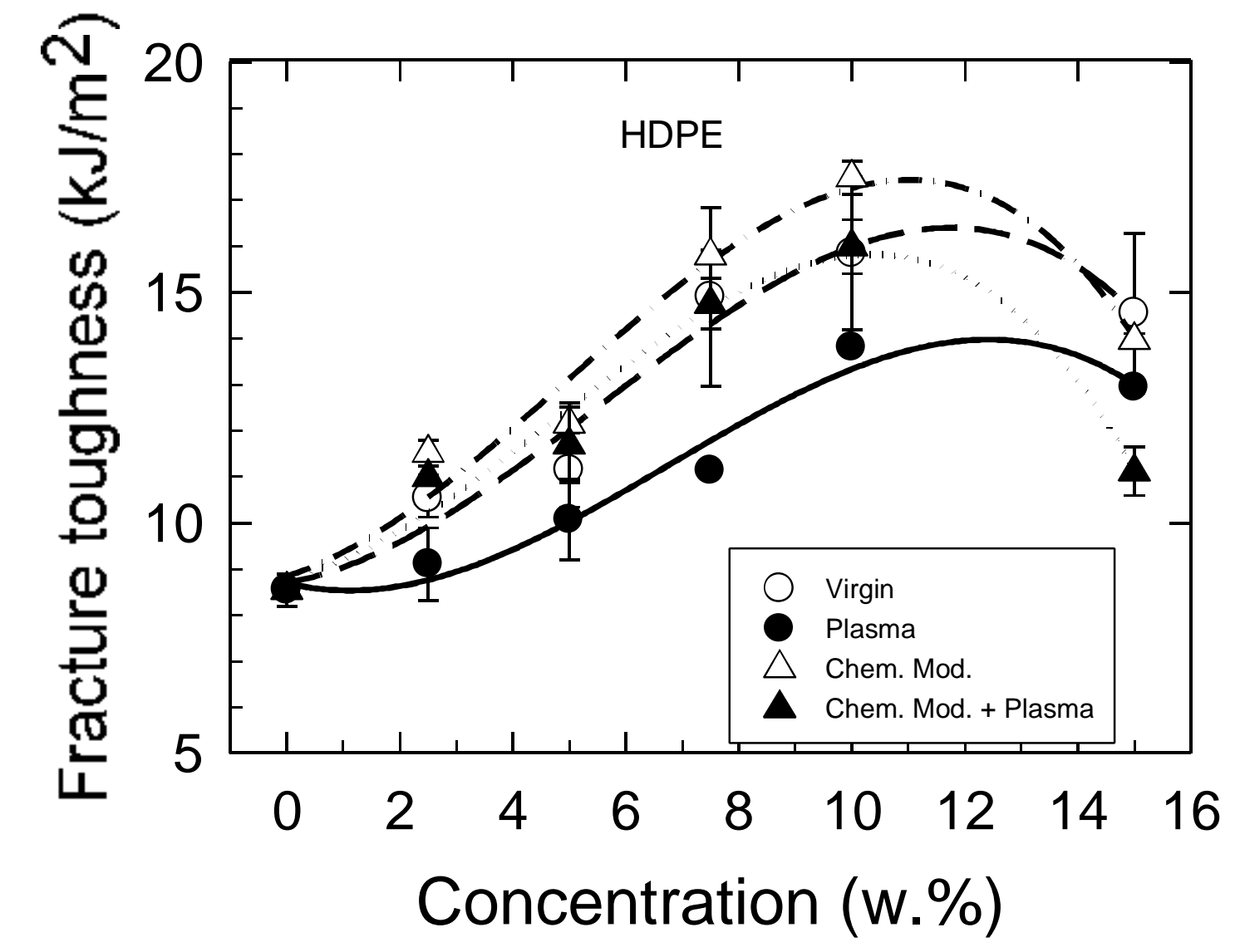

Fig.7. 


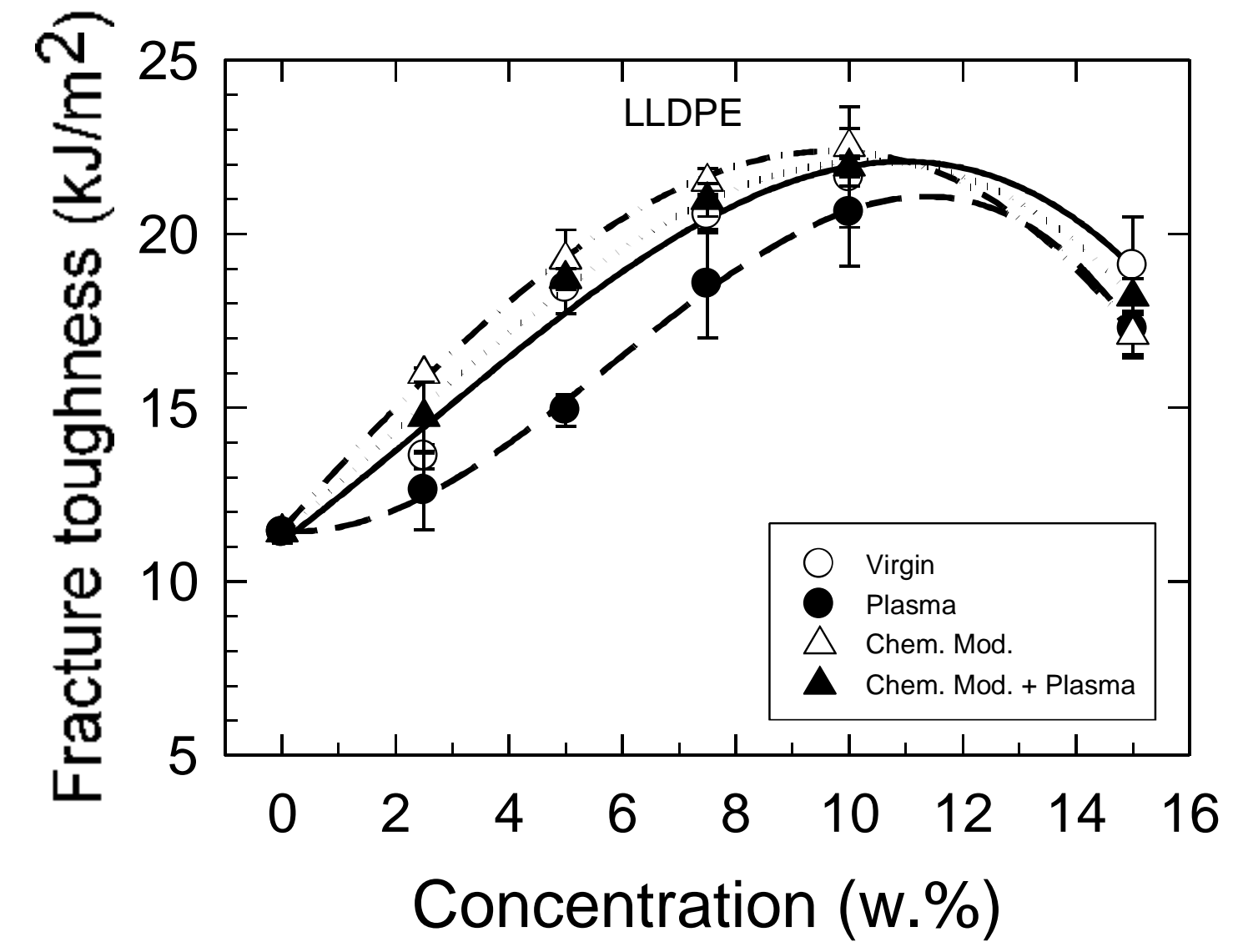

Fig.8. 


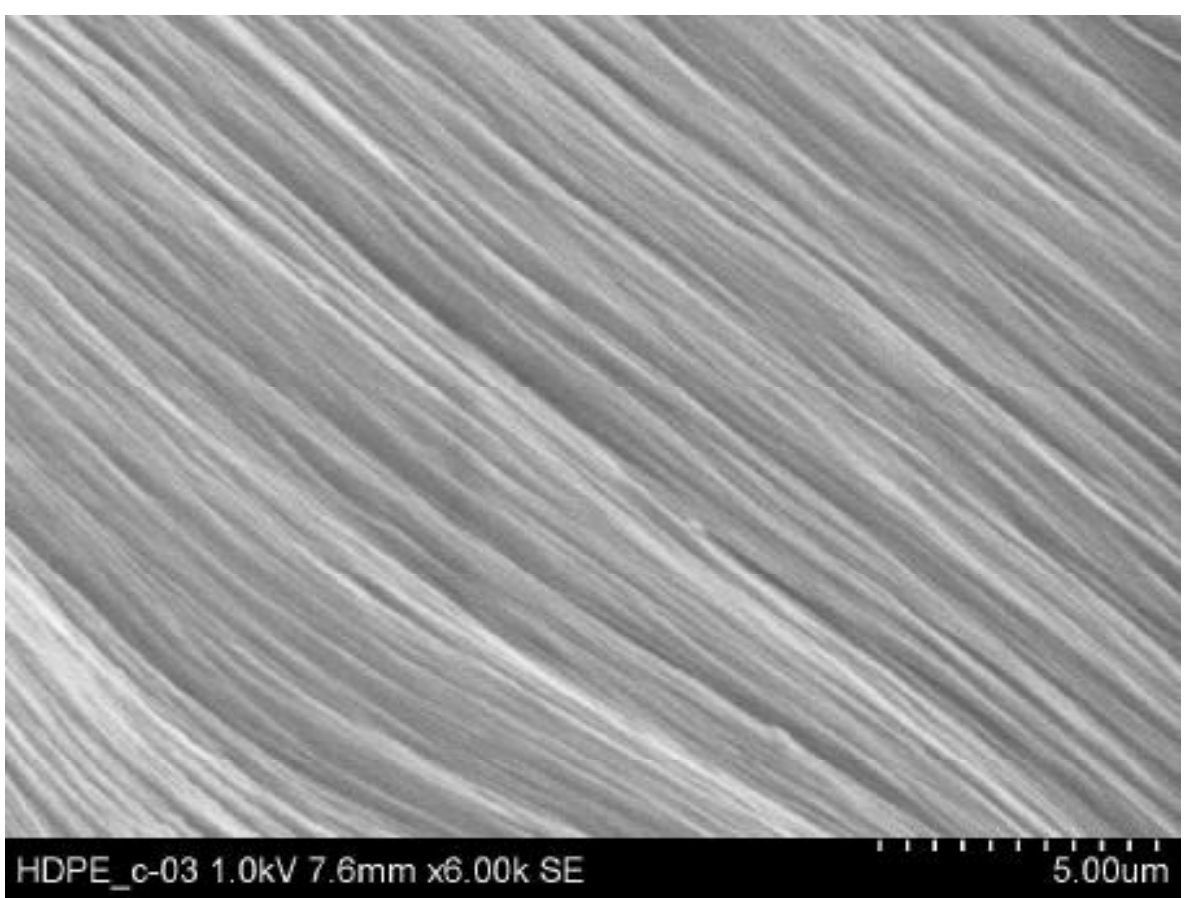

Fig.9. 


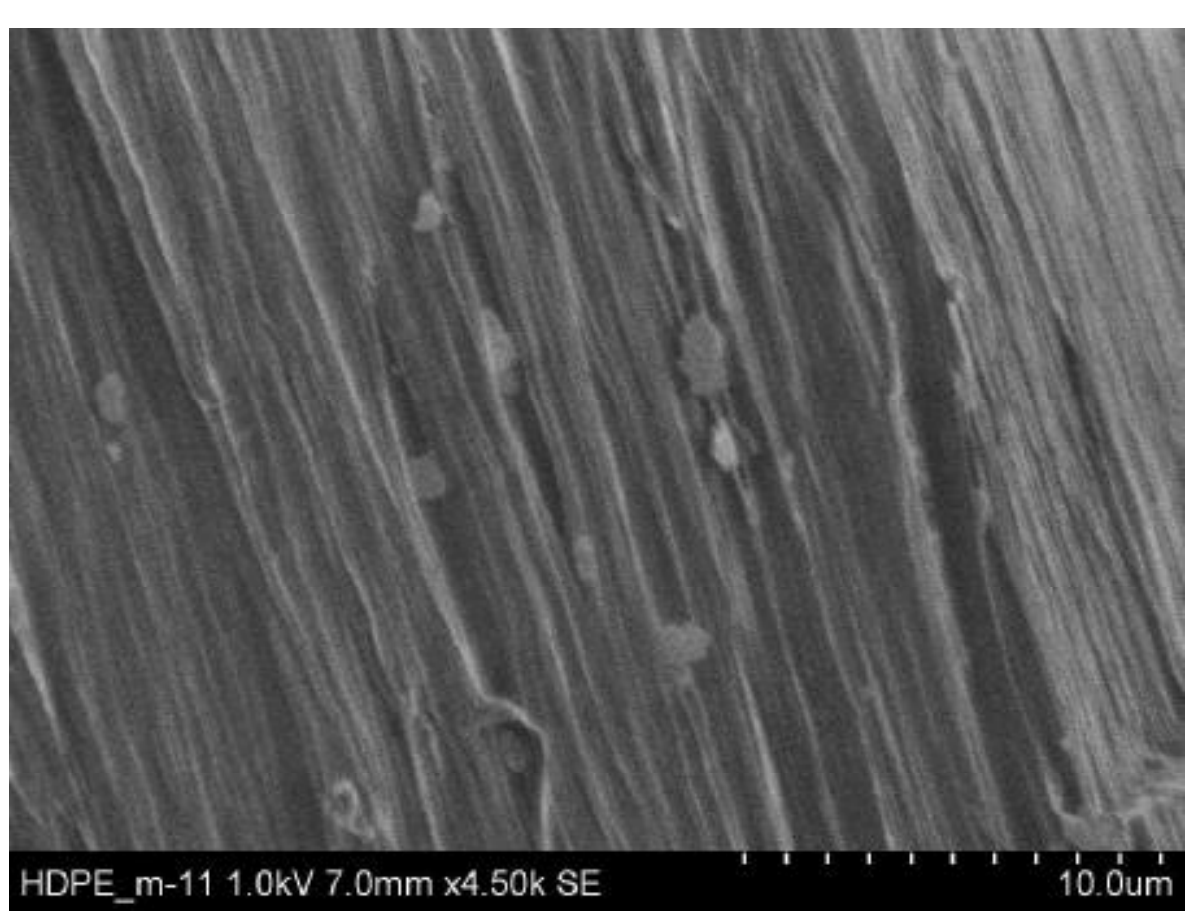

Fig.10. 


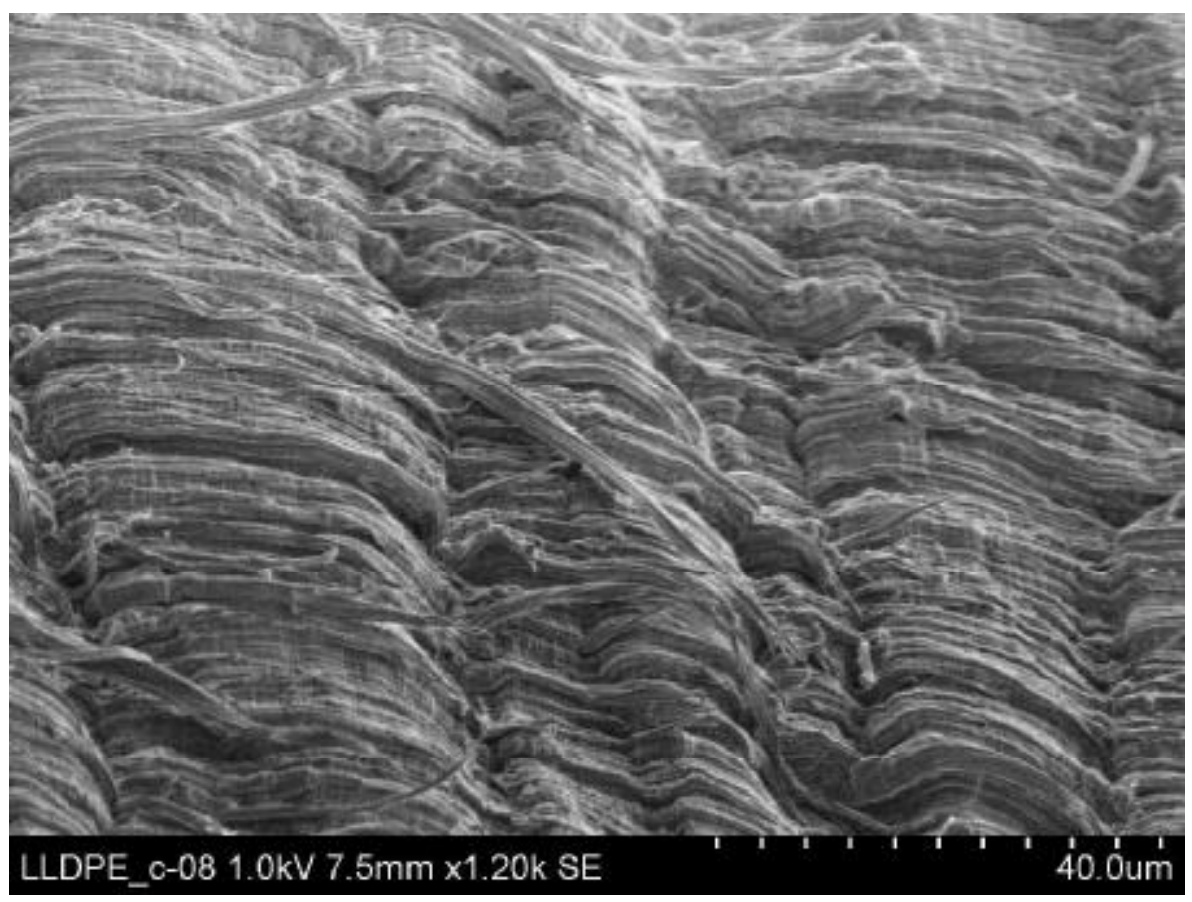

Fig.11. 


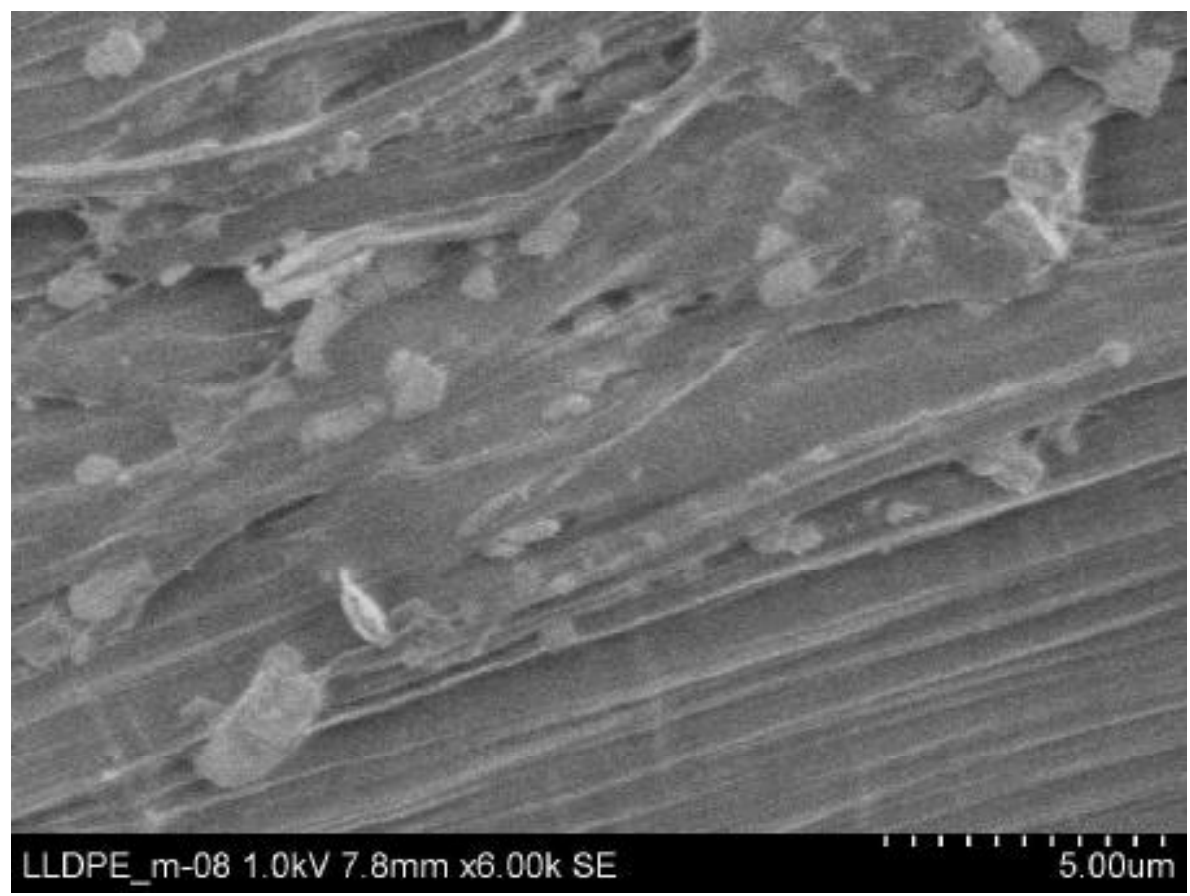

Fig.12. 


\section{Table caption:}

Table 1: Processing parameters of injection molding machine.

Table 2: Mechanical properties of HDPE samples with different untreated kaolinite filler contents.

Table 3: Mechanical properties of HDPE samples with different plasma treated kaolinite filler contents.

Table 4: Mechanical properties of silane coupled HDPE samples modified with different untreated kaolinite filler contents.

Table 5: Results of the TG DTG experiments of studied HDPE/kaolin and LLDPE/kaolin composites. 
Table 1: Processing parameters of injection molding machine

\begin{tabular}{lcc}
\hline & HDPE & LLDPE \\
\hline Temperature $\left({ }^{\circ} \mathrm{C}\right)$ & $160-180$ & $200-230$ \\
Injection speed $(\mathrm{mm} / \mathrm{s})$ & 50.0 & 40.0 \\
Pressure (bar) & 1000 & 1200 \\
Cooling time (s) & 15 & 15 \\
\hline
\end{tabular}


Table 2: Mechanical properties of HDPE samples with different untreated kaolinite filler contents.

\begin{tabular}{crrcccc}
\hline \multirow{2}{*}{$\begin{array}{c}\text { Filler } \\
\text { concentration }\end{array}$} & \multicolumn{6}{c}{ Deformation rate $(\mathrm{mm} / \mathrm{min})$} \\
\cline { 2 - 7 }$($ wt. \%) & $\mathrm{F}_{\max }(\mathrm{MPa})$ & $6[\%]$ & $\mathrm{E}(\mathrm{MPa})$ & $\mathrm{F}_{\max }(\mathrm{MPa})$ & $6[\%]$ & $\mathrm{E}(\mathrm{MPa})$ \\
\cline { 2 - 7 } & & & & & & \\
\hline 0 & $30.50 \pm 0.17$ & $24.00 \pm 0.34$ & $1523.00 \pm 2.54$ & $33.10 \pm 0.10$ & $17.13 \pm 0.27$ & $1635.00 \pm 2.00$ \\
2.5 & $30.97 \pm 0.26$ & $23.00 \pm 0.44$ & $1799.33 \pm 1.08$ & $33.73 \pm 0.16$ & $16.33 \pm 0.29$ & $1789.33 \pm 2.14$ \\
5 & $31.10 \pm 0.17$ & $18.55 \pm 0.27$ & $1902.50 \pm 2.89$ & $33.78 \pm 0.21$ & $13.28 \pm 0.30$ & $1862.50 \pm 1.79$ \\
7.5 & $31.13 \pm 0.33$ & $19.27 \pm 0.69$ & $1957.67 \pm 2.77$ & $33.47 \pm 0.33$ & $12.30 \pm 0.29$ & $1863.33 \pm 2.74$ \\
10 & $31.15 \pm 0.21$ & $16.43 \pm 0.32$ & $1987.50 \pm 1.58$ & $33.08 \pm 0.27$ & $10.50 \pm 0.44$ & $1897.50 \pm 1.63$ \\
15 & $30.99 \pm 0.20$ & $11.98 \pm 0.37$ & $2027.50 \pm 2.39$ & $33.00 \pm 0.34$ & $8.00 \pm 0.33$ & $1922.50 \pm 2.30$ \\
25 & $30.67 \pm 0.31$ & $8.43 \pm 0.53$ & $2043.33 \pm 3.29$ & $31.77 \pm 0.38$ & $6.73 \pm 0.43$ & $1900.66 \pm 2.05$ \\
\hline
\end{tabular}

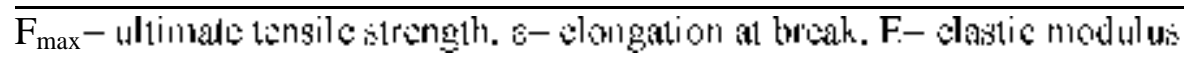


Table 3: Mechanical properties of HDPE samples with different plasma treated kaolinite filler contents.

\begin{tabular}{crrrrrr}
\hline \multirow{2}{*}{$\begin{array}{c}\text { Filler } \\
\text { concentration }\end{array}$ (wt. \%) } & \multicolumn{5}{c}{ Deformation rate $(\mathrm{mm} / \mathrm{min})$} \\
\cline { 2 - 7 } & $\mathrm{F}_{\max }(\mathrm{MPa})$ & $\varepsilon(\%)$ & $\mathrm{E}(\mathrm{MPa})$ & $\mathrm{F}_{\max }(\mathrm{MPa})$ & $\varepsilon\left({ }^{\circ}\right)$ & $\mathrm{E}(\mathrm{MPa})$ \\
\hline 0 & $30.50 \pm 0.17$ & $24.00 \pm 0.34$ & $1523.00 \pm 2.54$ & $33.10 \pm 0.10$ & $17.13 \pm 0.27$ & $1635.00 \pm 2.00$ \\
2.5 & $31.00 \pm 0.08$ & $22.80 \pm 0.35$ & $1630.67 \pm 0.98$ & $33.50 \pm 0.25$ & $15.33 \pm 0.57$ & $1673.33 \pm 2.42$ \\
5 & $30.95 \pm 0.19$ & $17.55 \pm 0.39$ & $1696.67 \pm 2.33$ & $33.47 \pm 0.49$ & $12.07 \pm 0.48$ & $1696.67 \pm 2.26$ \\
7.5 & $30.70 \pm 0.10$ & $17.33 \pm 0.46$ & $1770.00 \pm 2.40$ & $33.03 \pm 0.28$ & $11.33 \pm 0.28$ & $1730.00 \pm 2.76$ \\
10 & $30.30 \pm 0.27$ & $13.75 \pm 0.50$ & $1785.00 \pm 2.03$ & $32.35 \pm 0.20$ & $9.93 \pm 0.34$ & $1775.00 \pm 2.04$ \\
15 & $30.18 \pm 0.19$ & $10.50 \pm 0.45$ & $1907.50 \pm 2.56$ & $31.83 \pm 0.31$ & $7.63 \pm 0.41$ & $1695.33 \pm 1.29$ \\
25 & $29.67 \pm 0.41$ & $7.83 \pm 0.78$ & $1997.67 \pm 2.63$ & $31.67 \pm 0.34$ & $7.80 \pm 0.42$ & $1680.00 \pm 2.42$ \\
\hline
\end{tabular}

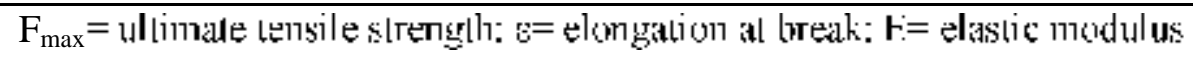


Table 4: Mechanical properties of HDPE/kaolinite samples modified with silane coupling agent (3aminopropyl)triethoxysilane.

\begin{tabular}{ccccccc}
\hline \multirow{2}{*}{$\begin{array}{c}\text { Filler } \\
\text { concentration }\end{array}($ wt. \%) } & \multicolumn{5}{c}{ Deformation rate $(\mathrm{mm} / \mathrm{min})$} \\
\cline { 2 - 7 } & $\mathrm{F}_{\max }(\mathrm{MPa})$ & $\varepsilon(\%)$ & $\mathrm{E}(\mathrm{MPa})$ & $\mathrm{F}_{\max }(\mathrm{MPa})$ & $\varepsilon(\%)$ & $\mathrm{E}(\mathrm{MPa})$ \\
\hline 0 & $30.50 \pm 0.35$ & $24.00 \pm 0.14$ & $1523.00 \pm 2.54$ & $33.10 \pm 0.10$ & $17.13 \pm 0.27$ & $1635.00 \pm 2.00$ \\
2.5 & $31.73 \pm 0.58$ & $21.67 \pm 0.25$ & $1843.67 \pm 2.71$ & $33.93 \pm 0.26$ & $16.43 \pm 0.53$ & $1767.33 \pm 1.81$ \\
5 & $31.93 \pm 0.29$ & $21.27 \pm 0.19$ & $1923.67 \pm 2.33$ & $34.03 \pm 0.19$ & $14.40 \pm 0.30$ & $1845.33 \pm 1.91$ \\
7.5 & $32.00 \pm 0.26$ & $17.33 \pm 0.06$ & $1960.00 \pm 1.70$ & $33.83 \pm 0.31$ & $14.39 \pm 0.37$ & $1886.67 \pm 1.60$ \\
10 & $31.67 \pm 0.22$ & $17.40 \pm 0.10$ & $1990.00 \pm 2.10$ & $33.33 \pm 0.22$ & $13.30 \pm 0.51$ & $1943.33 \pm 2.26$ \\
15 & $31.47 \pm 0.09$ & $15.03 \pm 0.15$ & $2006.50 \pm 1.93$ & $33.32 \pm 0.23$ & $13.07 \pm 0.61$ & $1965.00 \pm 1.29$ \\
\hline
\end{tabular}

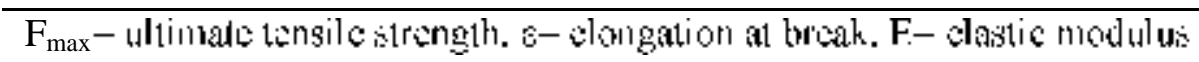


Table 5: Results of the TG DTG experiments of studied HDPE/kaolin and LLDPE/kaolin composites.

\begin{tabular}{|c|c|c|c|c|c|}
\hline \multirow{2}{*}{$\begin{array}{c}\text { Filler } \\
\text { concentration } \\
\text { (wt. \%) }\end{array}$} & \multicolumn{5}{|c|}{ HDPE/virgin kaolin } \\
\hline & $\begin{array}{l}\text { Weight } \\
\text { loss (\%) }\end{array}$ & $\mathrm{T}_{\mathrm{m}}\left({ }^{\circ} \mathrm{C}\right)$ & $\begin{array}{l}\frac{\Delta \mathrm{H}_{\mathrm{m}}}{(\mathrm{J} / \mathrm{g})} \\
\end{array}$ & $\mathrm{T}_{\mathrm{exo}}\left({ }^{\circ} \mathrm{C}\right)$ & $\mathrm{X}_{\mathrm{c}}(-)$ \\
\hline 0 & 100.0 & 131.5 & -196.2 & - & 0.670 \\
\hline 5 & 91.2 & 132.2 & -180.0 & 258.3 & 0.614 \\
\hline 10 & 97.7 & 132.0 & -184.9 & 255.0 & 0.631 \\
\hline 15 & 88.0 & 131.5 & -171.2 & 241.3 & 0.584 \\
\hline \multirow[t]{2}{*}{25} & 86.7 & 132.0 & -170.8 & 246.0 & 0.583 \\
\hline & \multicolumn{5}{|c|}{ HDPE/kaolin 10 min. air plasma treated } \\
\hline 5 & 95.7 & 132.0 & -188.6 & 265.0 & 0.635 \\
\hline 10 & 90.7 & 132.3 & -177.5 & 247.3 & 0.644 \\
\hline 15 & 89.0 & 131.6 & -180.1 & 238.8 & 0.606 \\
\hline \multirow[t]{2}{*}{25} & 95.3 & 130.7 & -186.1 & 264.7 & 0.615 \\
\hline & \multicolumn{5}{|c|}{ LLDPE/virgin kaolin } \\
\hline 0 & 100.0 & 130.5 & -189.5 & - & 0.647 \\
\hline 5 & 93.2 & 130.2 & -194.4 & 241.0 & 0.663 \\
\hline 10 & 84.7 & 130.2 & -160.9 & 231.0 & 0.549 \\
\hline 15 & 89.3 & 130.4 & -161.8 & 242.1 & 0.552 \\
\hline \multirow[t]{2}{*}{25} & 84.6 & 130.0 & -172.4 & 245.8 & 0.588 \\
\hline & \multicolumn{5}{|c|}{ LLDPE/kaolin 10 min. air plasma treated } \\
\hline 5 & 93.7 & 134.4 & -181.2 & 248.7 & 0.555 \\
\hline 10 & 84.8 & 133.4 & -167.0 & 237.1 & 0.618 \\
\hline 15 & 84.6 & 130.5 & -159.1 & 251.2 & 0.570 \\
\hline 25 & 89.6 & 130.2 & -162.5 & 237.3 & 0.543 \\
\hline
\end{tabular}

